\title{
High Prevalence of Human Papillomavirus in Colorectal Cancer in Hispanics: A Case-Control Study
}

\author{
Raul D. Bernabe-Dones, ${ }^{1,2}$ Maria Gonzalez-Pons, ${ }^{2}$ Alejandro Villar-Prados, ${ }^{2}$ \\ Mercedes Lacourt-Ventura, ${ }^{2}$ Heriberto Rodríguez-Arroyo, ${ }^{2}$ Sharon Fonseca-Williams, ${ }^{2}$ \\ Francisco E. Velazquez, ${ }^{2}$ Yaritza Diaz-Algorri, ${ }^{2}$ Sofia M. Lopez-Diaz, ${ }^{2}$ \\ Nayra Rodríguez, ${ }^{3}$ Yasuhiro Yamamura, ${ }^{3}$ and Marcia Cruz-Correa ${ }^{1,2,4}$ \\ ${ }^{1}$ School of Health Professions, University of Puerto Rico Medical Sciences Campus, San Juan, PR 00935, USA \\ ${ }^{2}$ Division of Gastrointestinal Oncology, University of Puerto Rico Comprehensive Cancer Center, San Juan, PR 00935, USA \\ ${ }^{3}$ AIDS Research Program, Ponce Health Sciences University School of Medicine, Ponce, PR, USA \\ ${ }^{4}$ Department of Surgery, Biochemistry and Medicine, University of Puerto Rico Medical Sciences Campus, San Juan, PR 00716, USA
}

Correspondence should be addressed to Marcia Cruz-Correa; marcia.cruzl@upr.edu

Received 2 July 2015; Accepted 11 October 2015

Academic Editor: Miguel Pera

Copyright (C) 2016 Raul D. Bernabe-Dones et al. This is an open access article distributed under the Creative Commons Attribution License, which permits unrestricted use, distribution, and reproduction in any medium, provided the original work is properly cited.

\begin{abstract}
The role of Human Papillomavirus (HPV) in colorectal carcinogenesis remains elusive. Based on the high incidence of HPVassociated malignancies among Puerto Rican Hispanics, this study aimed to assess the prevalence of HPV infection and viral integration in colorectal tissues in order to evaluate its putative role in colorectal cancer (CRC). In this case-control study, the prevalence of HPV infection in CRC (cases $n=45$ ) and normal colon mucosa from cancer-free subjects (controls $n=36$ ) was assessed by a nested PCR strategy. HPV-16 genotyping was performed in HPV-positive tissues and the physical status of the HPV16 genome was determined by E2 detection. HPV was detected in 19 of $45(42.2 \%)$ CRC cases (mean age $61.1 \pm 10.7$ years, 24 males) and in 1 of $36(2.8 \%)$ controls (mean age $60.9 \pm 9.6$ years, 24 males) with an OR $=25.58$ (95\% CI 3.21 to 203.49). HPV-16 was detected in $63.2 \%$ of the HPV-positive colorectal tumors; genome integration was observed in all HPV-16 positive cases. This is the first report showing the high prevalence of HPV infections in Caribbean Hispanic colorectal tumors. Despite evidence of HPV integration into the host genome, further mechanistic analysis examining HPV oncoprotein expression and the putative role of these oncoproteins in colorectal carcinogenesis is warranted.
\end{abstract}

\section{Introduction}

Human Papillomavirus (HPV) infections are the most common sexually transmitted infections in the United States (US) (http://www.cdc.gov/std/hpv/STDFact-HPV.htm). HPVs are epitheliotropic, double-stranded DNA viruses that infect the squamous epithelia of mucosal cells in the skin. Viral multiplication occurs in the cell nuclei and is tightly linked to the cell's differentiation state. There are well over 100 genotypes of HPV. Types 6, 11, 40, and 42 are commonly associated with benign lesions and are classified as low-risk types. HPV-16, HPV-18, HPV-31, and HPV-45 are considered to possess high oncogenic potential and are referred to as high-risk types [1,
2]. HPV has been identified as a causal agent in cervical [3-5], vaginal [6], anal [7], oral [8], and penile cancers [9]. Studies have also shown strong correlations between HPV and the development of many types of cancers such as esophagus [10], pharynx [11], and larynx [12]. However, the putative role of HPV infection in colorectal carcinogenesis has not been properly elucidated and still remains controversial.

The pathogenesis of CRC has become better understood at the molecular level; however, the etiology of CRC is still incompletely understood. In the last decade, several studies have suggested that HPV might have a role in colorectal carcinogenesis $[13,14]$. Detection of HPV in colonic tissue has led to a wide range of work proposing a causal association 
between HPV and CRC. The presence of HPV in colon tissue remains a highly controversial topic of discussion because of inconsistencies in result reproducibility. Since integration of the HPV genome is necessary for the virus to exert its carcinogenic potential, assessment of the physical status of the viral genome after confirming HPV infection is essential to establish a causal association. Inactivation of the E2 gene through genomic integration promotes the expression of the E6 and E7 oncoproteins, which antagonize the function of p53 and pRB, respectively $[4,15]$. The resulting degradation of p53 and pRB mediated by these oncoproteins facilitates viral DNA proliferation within the host and leads to neoplasia by mechanisms well described throughout the literature $[16,17]$.

CRC is responsible for approximately 694,000 deaths worldwide [18]. In the USA, CRC is the 3rd most commonly diagnosed cancer and the 3rd leading cause of cancer death [19]. In Puerto Rico (PR), CRC is the 2nd most diagnosed and the leading cause of cancer death among men and women [20]. A high prevalence of HPV-related cancers [21-23] and a high prevalence of HPV in anogenital samples have been reported among Puerto Rican men and women [24]. The seroprevalence of HPV-16 was reported to be $11.3 \%$ in a population-based sample of adults in PR [25], which is similar to that reported in the USA (11.5\%) [26]. Thus, given the high CRC mortality rates and the high incidence of HPV related morbidities in PR, the overall aim of this case-control study was to evaluate the association between CRC and HPV infection in samples from Puerto Rican Hispanics.

\section{Methods}

2.1. Ethics Statement. This study was approved by the University of Puerto Rico Medical Sciences Campus IRB (\#A7330109). All procedures were in accordance with the ethical standards of the IRB.

2.2. Subject Recruitment and Sample Acquisition. Cases and controls were recruited consecutively using convenience sampling and were frequency-matched by gender and age. Study participants aged 21 years or older were recruited when they visited the Puerto Rico Medical Center facilities for colonoscopies due to routine screening, symptoms, and/or referrals by gastroenterologists and colorectal surgeons. The purpose of this study was explained and all study participants gave informed consent prior to inclusion. All of the participants included in this analysis were Hispanics. Being Hispanic was defined by the participant's self-reported heritage or place of birth. All of the control subjects included in this study had normal results in their colonoscopy. Individuals with CRC had a diagnosis of adenocarcinoma confirmed by histopathology. Subjects with hereditary cancer syndromes and inflammatory bowel disease were excluded.

Fresh frozen tissue was obtained from 45 nonfamilial, sporadic CRC patients (cases) and 36 cancer-free individuals (controls). Tissues were harvested from CRC patients during tumor resection surgery. Anal or perianal tumors and tissue samples from individuals who reported to be HIV-positive were excluded. Tumor location was classified as proximal (from the cecum to the distal transverse colon), distal (from the splenic flexure to the sigmoid colon), or rectum (last $20 \mathrm{~cm}$ of the colon). Control colorectal tissue biopsies were obtained from the distal colon during routine colonoscopies.

Using the Collaborative Family Registries' Colorectal Cancer Risk Factor Questionnaire (http://coloncfr.org/), clinical and sociodemographic data was collected from each patient including gender, lifestyle, medical history, and family history of cancer. The sociodemographic and clinical characteristics analyzed in the study were gender (male versus female), median age ( $<61$ years versus $\geq 61$ years), type $2 \mathrm{DM}$ diagnosis (yes versus no), family history of any cancer (yes versus no), and family history of CRC (yes versus no). Family history is defined as having a first-, second-, or third-degree relative with cancer. The lifestyle characteristics that were analyzed in this study were alcohol consumption (ever versus never) and smoking status (ever versus never).

\subsection{DNA Extraction. Genomic DNA (gDNA) was extracted} from $\approx 100 \mathrm{mg}$ of tissue using the DNA Isolation Kit for Cells and Tissues (Roche Applied Science, Indianapolis, IN) following the manufacturer's instructions. For quality control purposes, $\beta$-actin gene PCR amplification was used to assess gDNA integrity; samples from which $\beta$-actin could not be amplified were excluded from the study.

The following standardized precautions were taken to minimize sample-to-sample cross-contamination: all instruments and work benches were wiped down with DNAZap (Ambion, Foster City, CA), followed by $10 \%$ bleach and $70 \%$ ETOH prior to sample manipulation. New, sterile blades were used for each sample. Tissue processing and nucleotide extraction were limited to a maximum of 10 samples per day. Approximately $100 \mathrm{mg}$ of each specimen was randomly coded in a blinded manner and used for further analyses.

2.4. HPV Detection and Genotyping. Human HPV DNA detection was performed via a nested PCR strategy using PGMY09/PGMY11 as outer primers and GP5+/GP6+ as inner primers $[27,28]$. These primers amplify an HPV L1 consensus region that detects more than $25 \mathrm{HPV}$ types. Each reaction was carried out in a total volume of $25 \mu \mathrm{L}$ containing $200 \mathrm{ng}$ of gDNA, $12.5 \mu \mathrm{L}$ of Bullseye HS-Taq $2 \mathrm{x}$ Master Mix (MidSci, St. Louis, MO), and $100 \mathrm{nmol} / \mathrm{L}$ of pooled PGMY09/11 primers. The following conditions were used: 15 minutes at $95^{\circ} \mathrm{C}$, followed by 35 cycles of 60 seconds each at $94^{\circ} \mathrm{C}, 60^{\circ} \mathrm{C}$, and $72^{\circ} \mathrm{C}$, with a final extension of 10 minutes at $72^{\circ} \mathrm{C}$. Two microliters of the first PCR reaction was used as the template for the nested PCR. The conditions for the nested PCR were identical to the first run PCR with the exception of the annealing temperature which was $52^{\circ} \mathrm{C}$. Amplified products were electrophoresed and analyzed using a ChemiDoc (Bio-Rad, Hercules, CA). Detection of pHPV-16 purified plasmid DNA (ATCC 45113D) was used as a positive control and water as a negative control.

HPV-16 DNA genotyping was carried out with the typespecific primers targeting HPV-16 E6 [13]. HPV-16E6 Pr80 (5' -CTGACTCGAG/TTTATGCACCAAAAGAGAAC- ${ }^{\prime}$ ) and Pr625 (5'-GATCAGTTGTCTCTGGTTGC-3') primers 
TABLE 1: Summary of demographic and clinical history characteristics of the study participants.

\begin{tabular}{|c|c|c|c|c|}
\hline Characteristics & & $\begin{array}{c}\text { CRC cases } \\
n=45 \\
n(\%)\end{array}$ & $\begin{array}{c}\text { Controls } \\
n=36 \\
n(\%)\end{array}$ & $p$ value \\
\hline \multicolumn{5}{|l|}{ Gender } \\
\hline Male & & $24(53.3)$ & $15(41.7)$ & 0.30 \\
\hline Female & & $21(46.7)$ & $21(58.3)$ & Reference \\
\hline Age median & & $61(38-86)$ & $60(42-85)$ & \\
\hline$\geq 61$ & & $23(51.1)$ & $18(50)$ & 0.92 \\
\hline$<61$ & & $22(48.9)$ & $18(50)$ & Reference \\
\hline \multicolumn{5}{|l|}{ Lifestyle } \\
\hline \multirow{2}{*}{ Ever smoked cigarettes } & Yes & $24(53.3)$ & $14(38.9)$ & 0.20 \\
\hline & No & $21(46.7)$ & $22(61.1)$ & Reference \\
\hline \multirow{2}{*}{ Ever drunk alcohol } & Yes & $25(55.6)$ & $15(41.7)$ & 0.21 \\
\hline & No & $20(44.4)$ & $21(58.3)$ & Reference \\
\hline \multicolumn{5}{|l|}{ Clinical history } \\
\hline \multirow{2}{*}{ Diabetes diagnosis } & Yes & $11(25.6)$ & $6(17.1)$ & 0.37 \\
\hline & No & $32(74.4)$ & $29(82.9)$ & Reference \\
\hline \multirow{2}{*}{ Family history of any cancer } & Yes & $32(71.1)$ & $29(82.9)$ & 0.22 \\
\hline & No & $13(28.9)$ & $6(17.1)$ & Reference \\
\hline \multirow{2}{*}{ Family history of CRC } & Yes & $8(17.8)$ & $15(42.8)$ & 0.01 \\
\hline & No & $37(82.2)$ & $20(57.1)$ & Reference \\
\hline
\end{tabular}

The number of cases may vary between categories according to the availability of the information. $p$ values were calculated using chi-square tests or Fisher's exact tests, when appropriate.

were used for the first run, with the same PCR conditions described above with the exception of the annealing temperature which was $68^{\circ} \mathrm{C}$. The conditions for the nested PCR with primers Pr106: $5^{\prime}$-GTTTCAGGACCCACAGGAGC- $3^{\prime}$ and Pr562: $5^{\prime}$-GTACTCACC CC/TGATTACAGCTGGGTTT C$3^{\prime}$ were the same with the exception of the annealing temperature which was $60^{\circ} \mathrm{C}$. Detection of the pHPV-16 purified plasmid DNA (ATCC 45113D) and water were used as positive and negative controls, respectively. Amplicons were electrophoresed and visualized as described. Ten percent of the samples tested by nested PCR were externally validated and confirmed at the AIDS Research Program Laboratory at the Ponce School of Medicine \& Health Sciences (Ponce, PR) using the INNO-LiPA HPV Genotyping Extra kit (Fujirebio, Gent, Belgium).

2.5. HPV Physical Status. The physical status of the HPV-16 genome was determined by examining E2 sequence integrity using a previously described nested PCR strategy [29]. All tumors harboring HPV-16 DNA were analyzed $(n=12)$. Nested PCR analysis was performed using 2 sets of specific HPV-16 primers which included 2 forward primers, Pr7581 $\left(5^{\prime}\right.$-CACTGCTTGCCAACCATTCC- $\left.3^{\prime}\right)$ and Pr7677 (5'GCC AAC GCC TTA CAT ACC G- $3^{\prime}$ ), and 2 reverse primers, $\operatorname{Pr} 128$ (5'-GTCGCTCCTGTGGGTCCTG-3') and Pr223 (5'ACGTCGCAGTAACTGTTGC- $\left.{ }^{\prime}\right)$. Both PCRs were performed under the same conditions previously described with the exception of the annealing temperature which was $60^{\circ} \mathrm{C}$. Amplicons were analyzed as described. DNA extracted from
CaSki (CRL-1550) and SiHa (HTB-35) human cervical cell lines were used as positive controls. The absence of PCR product was interpreted as E2 sequence disruption and integration of viral DNA into the host genome. The presence of E2 amplicons indicates the presence of episomal HPV-16 genomes.

2.6. Statistical Analysis. Sociodemographic, clinical, and lifestyle characteristics in cases and controls were described using frequency distributions for categorical variables and summary measures for quantitative variables. Two-sided tests were used to compare study groups: the chi-square test or Fisher's exact test was used for categorical variables and Student's $t$-test or Mann-Whitney test to compare quantitative variables. Unconditional logistic regression models were used to estimate the OR with $95 \%$ confidence of CRC in relation to HPV status and other variables. Statistical analyses were performed using SPSS 17.0 (SPSS Inc.) and Epi InfoTM 7 (CDC).

\section{Results}

3.1. Sociodemographic, Lifestyle, and Clinical History Characteristics of Study Participants. The demographic and clinical characteristics of the study population $(n=81 ; 45$ CRC cases and 36 controls) are presented in Table 1 . The mean age of the CRC cases was 61.1 years (ranging from 38 to 86 years; 24 were males). In the control group, the mean age was 60.9 years (ranging from 42 to 85 years; 15 were males). Compared 
TABLE 2: Association between HPV infection status and CRC.

\begin{tabular}{|c|c|c|c|c|}
\hline Characteristics & $\begin{array}{c}\text { CRC cases } \\
n=45 \\
n(\%)\end{array}$ & $\begin{array}{c}\text { Controls } \\
n=36 \\
n(\%)\end{array}$ & $p$ value & OR (95\% CI) \\
\hline \multicolumn{5}{|c|}{ HPV infection status } \\
\hline HPV (+) & $19(42.2)$ & $1(2.8)$ & \multirow{2}{*}{$p<0.001$} & $25.58(3.22-203.49)$ \\
\hline $\mathrm{HPV}(-)$ & $26(57.8)$ & $35(97.2)$ & & Reference \\
\hline \multicolumn{5}{|c|}{ HPV infection status per colorectal subsite } \\
\hline \multicolumn{5}{|l|}{ Proximal } \\
\hline HPV (+) & $4(8.9)$ & $1(2.8)$ & \multirow{2}{*}{$0.001^{* *}$} & $46.67(3.71-1175.05)^{*}$ \\
\hline $\mathrm{HPV}(-)$ & $3(6.7)$ & $35(97.2)$ & & Reference \\
\hline \multicolumn{5}{|l|}{ Distal } \\
\hline $\mathrm{HPV}(+)$ & $8(17.8)$ & $1(2.8)$ & \multirow{2}{*}{$p<0.001^{* *}$} & $25.46(3.32-582.87)^{*}$ \\
\hline $\mathrm{HPV}(-)$ & $11(24.5)$ & 35 (97.2) & & Reference \\
\hline \multicolumn{5}{|l|}{ Rectum } \\
\hline $\mathrm{HPV}(+)$ & $7(15.6)$ & $1(2.8)$ & \multirow{2}{*}{$0.002^{* *}$} & $20.42(2.62-474.77)^{*}$ \\
\hline $\mathrm{HPV}(-)$ & $12(26.7)$ & $35(97.2)$ & & Reference \\
\hline
\end{tabular}

$p$ values were calculated using chi-square tests or Fisher's exact tests, when appropriate. ${ }^{*}$ Mid- $p$ exact method; ${ }^{* *}$ Fisher's exact test.

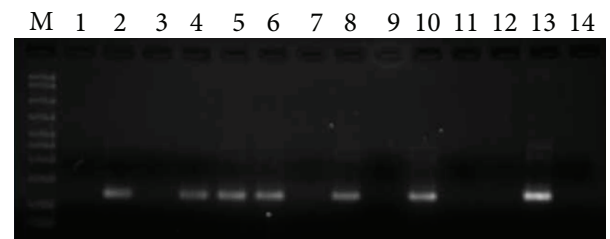

FIGURE 1: HPV detection assay. This figure shows the electrophotetic profile of 12 representative cases assayed by nested PCR for the detection of $H P V L 1$. Cases 2, 4, 5, 6, 8, and 10 are positive as demonstrated by the presence of the amplicon generated by the GP $5+/ 6+$ primer pair. Lane $\mathrm{M}$ is the molecular size marker; lanes 13 and 14 were HPV positive and water controls, respectively.

to controls, CRC cases were more likely to report a family history of CRC (OR $0.29 ; 95 \% 0.10-0.80)$. In terms of the ages of the family members with CRC as given by the subject, the median age of CRC diagnosis in the relatives of cases and controls was 60 years. No statistically significant associations were found when comparing cases and controls with relatives diagnosed with CRC at $\geq 60$ years versus $<60$ years. No other significant associations were found.

3.2. $H P V$ DNA Detection. A significant difference in the prevalence of HPV infection was observed when comparing colorectal tumor tissues and normal mucosa from controls. HPV DNA was detected in 19 of the 45 (42.2\%) CRC samples and in 1 of the $36(2.8 \%)$ control samples studied (Figure 1). HPV infection was positively associated with CRC (OR 25.58; 95\% CI 3.22 to 203.49), $p<0.001$ (Table 2). The association between HPV-positive status and CRC was observed throughout the anatomical regions of the colon.

3.3. Sociodemographic, Lifestyle, and Clinicopathological Characteristics of HPV-Positive Cases. The mean age of the
HPV-positive CRC cases was 60.3 years (ranging from 45 to $86 ; 9$ were males). No significant associations were found between HPV-positive status and the following: gender, age, use of tobacco or alcohol, history of diabetes, family history of any cancer, or family history of CRC (Table 3). No significant associations were observed between HPV status and histological differentiation, tumor stage, or location (Table 4).

3.4. HPV-16 Genotyping and Assessment of Viral Physical Status. HPV-16 was detected in 12 of the $19 \mathrm{HPV}$-positive CRC samples $(63.2 \%)$; the remaining $7(36.8 \%)$ corresponded to other HPV genotypes (nontyped). HPV-16 was not detected in the HPV-positive control sample. The distributions of HPV-16 positive tumors regarding tumor location were as follows: $33.3 \%$ (4 of 12) of the samples were found in the proximal colon (cecum, ascending colon, and transverse colon), $50.0 \%$ (6 of 12) were found in the distal colon (splenic flexure, descending colon, and sigmoid colon), and $16.7 \%$ (2 of 12) were detected in the rectum. For non-HPV-16 tumors, 2 out of $7(28.6 \%)$ were located in the distal colon and out 5 of $7(71.43 \%)$ were found in the rectum. The physical status of HPV-16 DNA in CRC tissues was determined by detection of HPV-16 E2. The amplicon corresponding to the intact E2 was not detected in any of the HPV-16 positive cases indicating that the HPV-16 genome was integrated.

\section{Discussion and Conclusions}

HPV has been detected in colorectal tumors [13, 30-33]. However, the role of HPV in colorectal carcinogenesis has not been elucidated and the subject remains controversial. In the current investigation, we report a rigorous evaluation of HPV infections in colorectal tissues (CRC cases and normal mucosa controls) from a well-characterized Hispanic 
TABLE 3: Summary of the demographic, lifestyle, and clinical characteristics of the CRC cases according to HPV status.

\begin{tabular}{|c|c|c|c|c|c|}
\hline & & $\begin{array}{c}\mathrm{HPV}(+) \mathrm{CRC} \\
n=19 \\
n(\%)\end{array}$ & $\begin{array}{c}\mathrm{HPV}(-) \mathrm{CRC} \\
n=26 \\
n(\%)\end{array}$ & $p$ value & OR (95\% CI) \\
\hline \multicolumn{6}{|l|}{ Gender } \\
\hline Male & & $9(47.4)$ & $15(57.7)$ & \multirow{2}{*}{0.49} & $0.66(0.20-2.17)$ \\
\hline Female & & $10(52.6)$ & $11(42.3)$ & & Reference \\
\hline Age median & & $59(45-86)$ & $61.5(38-83)$ & & \\
\hline$\geq 61$ & & $8(42.1)$ & $15(57.7)$ & \multirow{2}{*}{0.30} & $0.53(0.16-1.77)$ \\
\hline$<61$ & & $11(57.9)$ & $11(42.3)$ & & Reference \\
\hline \multicolumn{6}{|l|}{ Lifestyle } \\
\hline \multirow{2}{*}{ Ever smoked cigarettes } & Yes & $9(47.4)$ & $15(57.7)$ & \multirow{2}{*}{0.49} & $0.66(0.20-2.17)$ \\
\hline & No & $10(52.6)$ & $11(42.3)$ & & Reference \\
\hline \multirow{2}{*}{ Ever drunk alcohol } & Yes & $9(47.4)$ & $16(61.5)$ & \multirow{2}{*}{0.35} & $0.56(0.17-1.86)$ \\
\hline & No & $10(52.6)$ & $10(38.5)$ & & Reference \\
\hline \multicolumn{6}{|l|}{ Clinical history } \\
\hline \multirow{2}{*}{ Diabetes diagnosis } & Yes & $4(21.1)$ & $7(29.1)$ & \multirow{2}{*}{$0.73^{* *}$} & $0.65(0.14-2.73)^{*}$ \\
\hline & No & $15(78.9)$ & $17(70.8)$ & & Reference \\
\hline \multirow{2}{*}{ Family history of any cancer } & Yes & $16(84.2)$ & $16(61.5)$ & \multirow{2}{*}{0.10} & $3.33(0.77-14.42)$ \\
\hline & No & $3(15.8)$ & $10(38.5)$ & & Reference \\
\hline \multirow{2}{*}{ Family history of CRC } & Yes & $3(15.8)$ & $5(19.2)$ & \multirow{2}{*}{$p>0.99^{* *}$} & $0.79(0.14-3.95)^{*}$ \\
\hline & No & $16(84.2)$ & $21(80.8)$ & & Reference \\
\hline
\end{tabular}

The number of cases may vary between categories according to the availability of the information.

$p$ values were calculated using chi-square tests or Fisher's exact tests, when appropriate. ${ }^{*}$ Mid- $p$ exact method; ${ }^{* *}$ Fisher's exact test.

TABLE 4: Clinicopathological characteristics of colorectal tumors according to HPV status.

\begin{tabular}{|c|c|c|c|c|}
\hline & $\begin{array}{c}\mathrm{HPV}(+) \mathrm{CRC} \\
n=19 \\
n(\%)\end{array}$ & $\begin{array}{c}\mathrm{HPV}(-) \mathrm{CRC} \\
n=26 \\
n(\%)\end{array}$ & $p$ value & OR (95\% CI) \\
\hline \multicolumn{5}{|l|}{ Differentiation } \\
\hline Poor & $1(5.3)$ & $1(3.8)$ & \multirow{2}{*}{$p>0.99^{* *}$} & $1.14(0.03-47.21)^{*}$ \\
\hline Well/moderate & $14(73.7)$ & $16(61.5)$ & & Reference \\
\hline \multicolumn{5}{|l|}{ Staging } \\
\hline Advanced (III and IV) & $7(38.9)$ & $6(37.5)$ & \multirow{2}{*}{0.93} & $1.06(0.27-4.24)$ \\
\hline Early (0, I, and II) & $11(61.1)$ & $10(62.5)$ & & Reference \\
\hline \multicolumn{5}{|l|}{ Tumor location } \\
\hline Proximal & $4(21.1)$ & $3(11.53)$ & \multirow{2}{*}{$0.43^{* *}$} & $2.04(0.37-12.16)^{*}$ \\
\hline Distal and rectum & $15(79.0)$ & $23(88.5)$ & & Reference \\
\hline
\end{tabular}

The number of cases may vary between categories according to the availability of the information. $p$ values were calculated using chi-square tests or Fisher's exact tests, when appropriate. ${ }^{*}$ Mid- $p$ exact method; ${ }^{* *}$ Fisher's exact test.

population reported to have a high incidence of HPVassociated malignancies [21-24] and a high CRC mortality rate [20]. HPV-16 genotyping and the physical status of the HPV-16 genome were also assessed.

A high prevalence of HPV infection (42.2\%) was detected in the tumor tissues analyzed. Only 1 of the 36 (2.8\%) control samples was positive for a non-HPV-16 type. The prevalence of HPV infections in colorectal tumors found in our cohort is comparable to percentages previously reported in studies from different countries using different experimental approaches [34]. Immunohistochemical analysis of formalin fixed paraffin-embedded (FFPE) tissue samples from individuals in the USA $(n=103 ; 30$ controls, 30 adenomas, and 43 CRC) detected HPV DNA in $27 \%$ and $69 \%$ of the adenomas and CRC, respectively [35]. HPV type-specific PCR analyses of DNA from FFPE samples from Chinese individuals detected HPV in $29 \%$ of the adenomas $(n=37)$ and in $53 \%$ of the CRC $(n=70)$ [36]. Using the same nested PCR strategy used in this study in combination with in situ PCR, another study detected HPV DNA in 51\% of the CRC samples $(n=55)$ and not in control samples $(n=10)$ from individuals in the USA [13]. Other studies using the same 
nested PCR strategy with CRC samples from Argentinean individuals detected HPV in $44 \%$ of CRC samples $(n=75)$ [31]. However, Pérez et al. (2005) reported that HPV was present in $33 \%$ of the nonneoplastic colorectal tissues studied $(n=30)$ [37]. In contrast, several studies have failed to detect $\mathrm{HPV}$ and have suggested that HPV infection is not a risk factor for CRC [38-41].

HPV-16 is the most common high-risk type in the Americas [30, 42]. HPV-16 has also been reported to be highly prevalent in HPV-associated malignancies in PR such as head and neck [43] and cervical cancer [44]. In our study, HPV-16 was the most prevalent high-risk HPV type detected; HPV16 was present in $63.2 \%$ of the HPV-positive CRC samples (12 of 19), which is comparable to some previous reports where HPV-16 was the most prevalent high-risk HPV type detected. Similarly, analysis of HPV-positive CRC samples using a PCR-based HPV-16 genotyping method found that it was the most frequently detected viral type, being present in 41 of the 60 cases $(68.3 \%)$ [14]. HPV-16 genotyping using the same primer pairs used in this study detected HPV-16 in 36\% of the CRC samples $(n=107)$ [13]. Using non-PCR-based HPV-16 genotyping techniques, HPV-16 has been found in 16-94\% of HPV-positive CRC samples [37, 45, 46].

The discrepancies in the literature reporting the detection of HPV and HPV-16 in colorectal tumors can be attributed to methodological differences including study design, type of tissue sample, sample size, sample collection, and differences in the sensitivity of the HPV detection or genotyping technique used. Frozen tissue samples were used because the DNA extracted is of superior quality compared to DNA from FFPE, which is degraded [47, 48]. The fixation procedure degrades DNA to fragments $<200 \mathrm{bp}$, which results in decreased PCR yields and the inability to amplify long targets [49]. Therefore, DNA extracted from FFPE is not optimal for the nested PCR strategy used in our analyses. The PGMY/GP+ primer set combination amplifies HPV L1 (450 bp). This primer combination has been found to be more type sensitive than the MY/GP+ primer sets, detecting a wider range of HPV types [50]. Additional differences in the detection of HPV in CRC have been associated with regional variations in the prevalence of HPV infection, which are influenced by the subject's racial/ethnic and geographical background [30, 34]. For example, HPV-18 is most frequently detected in CRC cases from Asia and Europe [30].

HPV was detected in CRC tissues in multiple tumor samples obtained throughout the colon. HPV was detected in $21.05 \%$ of proximal tumors, $42.11 \%$ of distal tumors, and $36.84 \%$ of the tumors in the rectum. The wide anatomical distribution of HPV infections in CRC tumor tissue implies that HPV infection in CRC is not a result of a retrograde viral transmission from the anogenital area. Given these results, we cannot discard the possibility of hematologic spread, as suggested by Bodaghi et al. [29]. There is evidence of HPV infections in infants and female university students who have never had penetrative sex, supporting that HPV transmission via other nonsexual routes may exist $[51,52]$. Although HPV is a sexually transmitted disease, we did not collect sexual behavior information, which would have allowed us to assess whether there is any association between CRC and sexual behavior.

Virus integration into the host genome is a critical step in cervical carcinogenesis. Integration of HPV in the host genome has been reported in approximately $90 \%$ of cervical carcinomas. These cases show expression of the E6 and E7 viral oncogenes [53]. The HPV physical status can be detected by the absence of a PCR product since the E2 open reading frame is disrupted when HPV integrates into the host genome [54]. Potential limitations using this method could include the following: the assay can only detect integrated viral DNA in the absence of episomal HPV DNA, it cannot discriminate between pure episomal and mixed forms, and the possibility of viral integration without losing the E2 gene fragment is not considered $[55,56]$. However, in our study, all of the HPV-16 positive cases tested showed integration, which discards the presence of episomal genomes. The high percentage of HPV-16 genome integration into the host genome supports the possibility that HPV may have a role in colorectal carcinogenesis. Our results, although encouraging, need to be interpreted cautiously. Despite the high prevalence of infection in colorectal tumors with a high-risk HPV type (HPV-16) and evidence of viral genome integration, future studies need to assess if the HPV infections are active and if the oncoproteins E6 and E7 are being expressed in order to contribute and/or have a causal role in colorectal carcinogenesis.

Our study has a relatively small sample size, which can be a limitation for stratified and restricted analyses. These could result in some imprecise estimates (as evidenced by the wide $95 \%$ confidence intervals). Nevertheless, the magnitude of the observed odds ratios for the association between HPV and CRC is very high and unlikely to result from a type I statistical error. The data generated in this study in combination with reports in the literature are not yet sufficient to conclude that HPV is a causative agent of CRC according to Bradford Hill's Criteria of Causation [57]. Five of the 9 postulated criteria are met. (1) Strength: strong statistically significant associations have been reported in this study and in the literature [30]. (2) Consistency: HPV has been detected in CRC in other studies using the same methodology [13, 31, 37]. (3) Plausibility: HPV integrates into the host genome and expresses oncogenic proteins known to promote carcinogenesis [16, 17]. (4) Analogy: high-risk HPVs, such as HPV-16, have a causal role in other cancers [6-9] such as cervical cancer [3-5]. (5) Temporality: HPV has also been detected in adenomas, CRC precursor lesions [35, 36]. Additional longitudinal studies evaluating the role of HPV during colorectal carcinogenesis are needed to fully support the consistency and temporality criterion. In conclusion, this study reports a high prevalence of HPV infection, a high prevalence of HPV-16 (a high-risk type), and integration of the HPV-16 genome in colorectal tumor tissue from Caribbean Hispanics. Further analyses are warranted in order to establish a causal association between HPV and CRC.

\section{Conflict of Interests}

The authors declared that there is no conflict of interests. 


\section{Acknowledgments}

This project was supported by RCMI Grant G12MD007600 and Grant U54MD007587 from the NIMHD. Additional support was provided by Grants R21CA167220 and U54CA096297 from the NCI. The authors would like to thank Dr. Ana Patricia Ortiz for critically reading this paper.

\section{References}

[1] F. X. Bosch and S. de Sanjosé, "The epidemiology of human papillomavirus infection and cervical cancer," Disease Markers, vol. 23, no. 4, pp. 213-227, 2007.

[2] A. R. Giuliano, G. Tortolero-Luna, E. Ferrer et al., "Epidemiology of human papillomavirus infection in men, cancers other than cervical and benign conditions," Vaccine, vol. 26, supplement 10, pp. K17-K28, 2008.

[3] F. X. Bosch and S. de Sanjosé, "Human papillomavirus in cervical cancer," Current Oncology Reports, vol. 4, no. 2, pp. 175$183,2002$.

[4] H. zur Hausen, "Papillomaviruses and cancer: from basic studies to clinical application," Nature Reviews Cancer, vol. 2, no. 5, pp. 342-350, 2002.

[5] M. Schiffman, P. E. Castle, J. Jeronimo, A. C. Rodriguez, and S. Wacholder, "Human papillomavirus and cervical cancer," The Lancet, vol. 370, no. 9590, pp. 890-907, 2007.

[6] B. S. Madsen, H. L. Jensen, A. J. C. van den Brule, J. Wohlfahrt, and M. Frisch, "Risk factors for invasive squamous cell carcinoma of the vulva and vagina-population-based case-control study in Denmark," International Journal of Cancer, vol. 122, no. 12, pp. 2827-2834, 2008.

[7] J. R. Daling, M. M. Madeleine, L. G. Johnson et al., "Human papillomavirus, smoking, and sexual practices in the etiology of anal cancer," Cancer, vol. 101, no. 2, pp. 270-280, 2004.

[8] J. M. Ritchie, E. M. Smith, K. F. Summersgill et al., "Human papillomavirus infection as a prognostic factor in carcinomas of the oral cavity and oropharynx," International Journal of Cancer, vol. 104, no. 3, pp. 336-344, 2003.

[9] M. A. Rubin, B. Kleter, M. Zhou et al., "Detection and typing of human papillomavirus DNA in penile carcinoma: evidence for multiple independent pathways of penile carcinogenesis," The American Journal of Pathology, vol. 159, no. 4, pp. 1211-1218, 2001.

[10] Z.-Y. Shen, S.-P. Hu, L.-C. Lu et al., "Detection of human papillomavirus in esophageal carcinoma," Journal of Medical Virology, vol. 68, no. 3, pp. 412-416, 2002.

[11] M. L. Gillison, W. M. Koch, R. B. Capone et al., "Evidence for a causal association between human papillomavirus and a subset of head and neck cancers," Journal of the National Cancer Institute, vol. 92, no. 9, pp. 709-720, 2000.

[12] H. Kaya, E. Kotiloğlu, S. Inanli et al., "Prevalence of human papillomavirus (HPV) DNA in larynx and lung carcinomas," Pathologica, vol. 93, no. 5, pp. 531-534, 2001.

[13] S. Bodaghi, K. Yamanegi, S.-Y. Xiao, M. Da Costa, J. M. Palefsky, and Z.-M. Zheng, "Colorectal papillomavirus infection in patients with colorectal cancer," Clinical Cancer Research, vol. 11, no. 8, pp. 2862-2867, 2005.

[14] D. C. Damin, M. B. Caetano, M. A. Rosito et al., "Evidence for an association of human papillomavirus infection and colorectal cancer," European Journal of Surgical Oncology, vol. 33, no. 5, pp. 569-574, 2007.

[15] Á. Buitrago-Pérez, G. Garaulet, A. Vázquez-Carballo, J. M. Paramio, and R. García-Escudero, "Molecular signature of HPV-induced carcinogenesis: pRb, p53 and gene expression profiling," Current Genomics, vol. 10, no. 1, pp. 26-34, 2009.

[16] M. Narisawa-Saito and T. Kiyono, "Basic mechanisms of highrisk human papillomavirus-induced carcinogenesis: roles of E6 and E7 proteins," Cancer Science, vol. 98, no. 10, pp. 1505-1511, 2007.

[17] T. Yugawa and T. Kiyono, "Molecular mechanisms of cervical carcinogenesis by high-risk human papillomaviruses: novel functions of E6 and E7 oncoproteins," Reviews in Medical Virology, vol. 19, no. 2, pp. 97-113, 2009.

[18] September 2014, http://globocan.iarc.fr.

[19] American Cancer Society, Colorectal Cancer Facts \& Figures 2014-2016, American Cancer Society, Atlanta, Ga, USA, 2014.

[20] G. Z.-Z. D. Tortolero-Luna, N. Perez-Rios, C. R. Torres-Cintron et al., Cancer in Puerto Rico, 2006-2010, Puerto Rico Central Cancer Registry Comprehensive Cancer Center, San Juan, Puerto Rico, 2013.

[21] E. Suárez, L. González, E. C. Díaz-Toro, W. A. Calo, F. Bermúdez, and A. P. Ortiz, "Incidence of oral cavity and pharyngeal cancers by anatomical sites in population-based registries in Puerto Rico and the United States of America," Puerto Rico Health Sciences Journal, vol. 32, no. 4, pp. 175-181, 2013.

[22] A. P. Ortiz, J. Romaguera, C. M. Pérez et al., "Human papillomavirus infection in women in Puerto Rico: agreement between physician-collected and self-collected anogenital specimens," Journal of Lower Genital Tract Disease, vol. 17, no. 2, pp. 210-217, 2013.

[23] V. Colón-López, A. P. Ortiz, and J. Palefsky, "Burden of human papillomavirus infection and related comorbidities in men: implications for research, disease prevention and health promotion among hispanic men," Puerto Rico Health Sciences Journal, vol. 29, no. 3, pp. 232-240, 2010.

[24] V. Colón-López, A. P. Ortiz, L. Del Toro-Mejías, M. C. Clatts, and J. M. Palefsky, "Epidemiology of anal HPV infection in high-risk men attending a sexually transmitted infection clinic in Puerto Rico," PLoS ONE, vol. 9, no. 1, Article ID e83209, 2014.

[25] A. P. Ortiz, E. R. Unger, C. Muñoz et al., "Cross-sectional study of HPV-16 infection in a population-based subsample of Hispanic adults," BMJ Open, vol. 4, no. 2, Article ID e004203, 2014.

[26] B. Liu and E. Taioli, "Associations between human papillomavirus and history of cancer among U.S. adults in the National Health and Nutrition Examination Survey (2003-2010)," British Journal of Cancer, vol. 111, no. 7, pp. 1448-1453, 2014.

[27] M. Evander, K. Edlund, E. Boden et al., "Comparison of a one-step and a two-step polymerase chain reaction with degenerate general primers in a population-based study of human papillomavirus infection in young Swedish women," Journal of Clinical Microbiology, vol. 30, no. 4, pp. 987-992, 1992.

[28] P. E. Gravitt, C. L. Peyton, T. Q. Alessi et al., "Improved amplification of genital human papillomaviruses," Journal of Clinical Microbiology, vol. 38, no. 1, pp. 357-361, 2000.

[29] S. Bodaghi, L. V. Wood, G. Roby, C. Ryder, S. M. Steinberg, and Z.-M. Zheng, "Could human papillomaviruses be spread through blood?" Journal of Clinical Microbiology, vol. 43, no. 11, pp. 5428-5434, 2005. 
[30] D. C. Damin, P. K. Ziegelmann, and A. P. Damin, "Human papillomavirus infection and colorectal cancer risk: a metaanalysis," Colorectal Disease, vol. 15, no. 8, pp. e420-e428, 2013.

[31] L. O. Pérez, G. Barbisan, A. Ottino, H. Pianzola, and C. D. Golijow, "Human papillomavirus DNA and oncogene alterations in colorectal tumors," Pathology and Oncology Research, vol. 16, no. 3, pp. 461-468, 2010.

[32] B. McGregor, P. Byrne, D. Kirgan, J. Albright, P. Manalo, and M. Hall, "Confirmation of the association of human papillomavirus with human colon cancer," The American Journal of Surgery, vol. 166, no. 6, pp. 738-742, 1993.

[33] N. Buyru, A. Tezol, and N. Dalay, "Coexistence of K-ras mutations and HPV infection in colon cancer," BMC Cancer, vol. 6, article 115, 2006.

[34] L. Lorenzon, M. Ferri, E. Pilozzi, M. R. Torrisi, V. Ziparo, and D. French, "Human papillomavirus and colorectal cancer: evidences and pitfalls of published literature," International Journal of Colorectal Disease, vol. 26, no. 2, pp. 135-142, 2011.

[35] D. Kirgan, P. Manalo, M. Hall, and B. McGregor, "Association of human papillomavirus and colon neoplasms," Archives of Surgery, vol. 125, no. 7, pp. 862-865, 1990.

[36] J. Y. Cheng, L. F. Sheu, C. L. Meng, W. H. Lee, and J. C. Lin, "Detection of human papillomavirus DNA in colorectal carcinomas by polymerase chain reaction," Gut, vol. 37 , no. 1 , pp. 87-90, 1995.

[37] L. O. Pérez, M. C. Abba, R. M. Laguens, and C. D. Golijow, "Analysis of adenocarcinoma of the colon and rectum: detection of human papillomavirus (HPV) DNA by polymerase chain reaction," Colorectal Disease, vol. 7, no. 5, pp. 492-495, 2005.

[38] A. N. Burnett-Hartman, P. A. Newcomb, M. T. Mandelson et al., "No evidence for human papillomavirus in the etiology of colorectal polyps," Cancer Epidemiology, Biomarkers \& Prevention, vol. 20, no. 10, pp. 2288-2292, 2011.

[39] M. C. Gornick, X. Castellsague, G. Sanchez et al., "Human papillomavirus is not associated with colorectal cancer in a large international study," Cancer Causes and Control, vol. 21, no. 5, pp. 737-743, 2010.

[40] D. Yavuzer, N. Karadayi, T. Salepci, H. Baloglu, R. Dabak, and O. U. Bayramicli, "Investigation of human papillomavirus DNA in colorectal carcinomas and adenomas," Medical Oncology, vol. 28, no. 1, pp. 127-132, 2011.

[41] K. V. Shah, R. W. Daniel, J. W. Simons, and B. Vogelstein, "Investigation of colon cancers for human papillomavirus genomic sequences by polymerase chain reaction," Journal of Surgical Oncology, vol. 51, no. 1, pp. 5-7, 1992.

[42] P. Guan, R. Howell-Jones, N. Li et al., "Human papillomavirus types in 115,789 HPV-positive women: a meta-analysis from cervical infection to cancer," International Journal of Cancer, vol. 131, no. 10, pp. 2349-2359, 2012.

[43] A. Báez, J. I. Almodóvar, A. Cantor et al., "High frequency of HPV16-associated head and neck squamous cell carcinoma in the Puerto Rican population," Head \& Neck, vol. 26, no. 9, pp. 778-784, 2004.

[44] K. Mendez, J. Romaguera, A. P. Ortiz, M. López, M. Steinau, and E. R. Unger, "Urine-based human papillomavirus DNA testing as a screening tool for cervical cancer in high-risk women," International Journal of Gynecology and Obstetrics, vol. 124, no. 2, pp. 151-155, 2014.

[45] F. Liu, X. Mou, N. Zhao, J. Lin, L. Teng, and C. Xiang, "Prevalence of human papillomavirus in Chinese patients with colorectal cancer," Colorectal Disease, vol. 13, no. 8, pp. 865-871, 2011.
[46] T.-H. Chen, C.-C. Huang, K.-T. Yeh et al., "Human papilloma virus 16 E6 oncoprotein associated with p53 inactivation in colorectal cancer," World Journal of Gastroenterology, vol. 18, no. 30, pp. 4051-4058, 2012.

[47] K. Specht, T. Richter, U. Müller, A. Walch, M. Werner, and H. Höfler, "Quantitative gene expression analysis in microdissected archival formalin-fixed and paraffin-embedded tumor tissue," The American Journal of Pathology, vol. 158, no. 2, pp. 419-429, 2001.

[48] W. J. Koskinen, R. W. Chen, I. Leivo et al., "Prevalence and physical status of human papillomavirus in squamous cell carcinomas of the head and neck," International Journal of Cancer, vol. 107, no. 3, pp. 401-406, 2003.

[49] N. Quach, M. F. Goodman, and D. Shibata, "In vitro mutation artifacts after formalin fixation and error prone translesion synthesis during PCR," BMC Clinical Pathology, vol. 4, no. 1, article 1, 2004.

[50] W. Qu, G. Jiang, Y. Cruz et al., "PCR detection of human papillomavirus: comparison between MY09/MY11 and GP5+/GP6+ primer systems," Journal of Clinical Microbiology, vol. 35, no. 6, pp. 1304-1310, 1997.

[51] J. Cason and C. A. Mant, "High-risk mucosal human papillomavirus infections during infancy \& childhood," Journal of Clinical Virology, vol. 32, supplement 1, pp. S52-S58, 2005.

[52] A. C.-H. Chen, A. Keleher, M.-A. Kedda, A. B. Spurdle, N. A. J. McMillan, and A. Antonsson, "Human papillomavirus DNA detected in peripheral blood samples from healthy Australian male blood donors," Journal of Medical Virology, vol. 81, no. 10, pp. 1792-1796, 2009.

[53] M. Pett and N. Coleman, "Integration of high-risk human papillomavirus: a key event in cervical carcinogenesis?" Journal of Pathology, vol. 212, no. 4, pp. 356-367, 2007.

[54] M. Durst, A. Kleinheinz, M. Hotz, and L. Gissmann, "The physical state of human papillomavirus type 16 DNA in benign and malignant genital tumours," Journal of General Virology, vol. 66, no. 7, pp. 1515-1522, 1985.

[55] S. Nagao, M. Yoshinouchi, Y. Miyagi et al., "Rapid and sensitive detection of physical status of human papillomavirus type 16 DNA by quantitative real-time PCR," Journal of Clinical Microbiology, vol. 40, no. 3, pp. 863-867, 2002.

[56] M. Saunier, S. Monnier-Benoit, F. Mauny et al., "Analysis of human papillomavirus type 16 (HPV16) DNA load and physical state for identification of HPV16-infected women with high-grade lesions or cervical carcinoma," Journal of Clinical Microbiology, vol. 46, no. 11, pp. 3678-3685, 2008.

[57] A. B. Hill, "The environment and disease: association or causation?" Proceedings of the Royal Society of Medicine, vol. 58, pp. 295-300, 1965. 


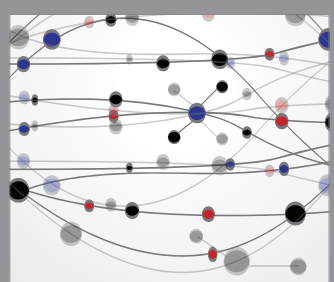

The Scientific World Journal
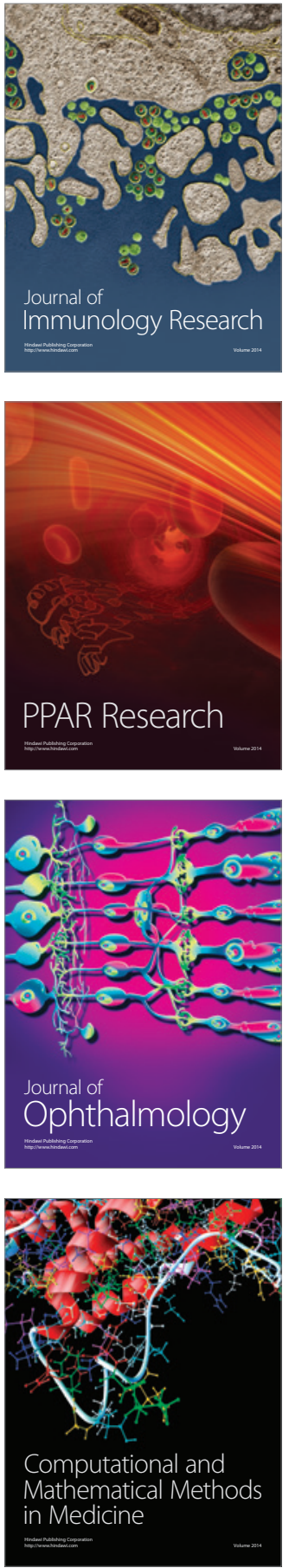

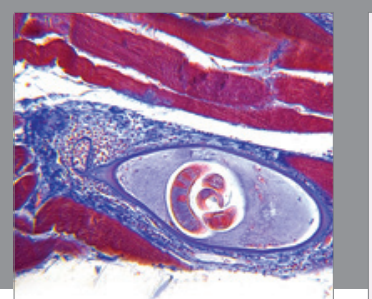

Gastroenterology Research and Practice

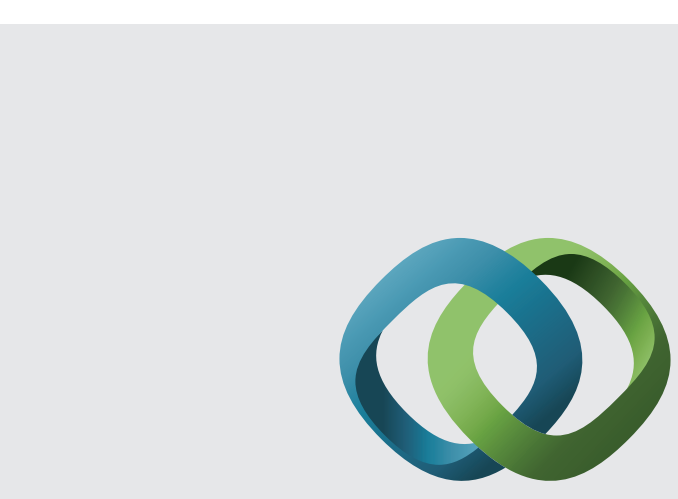

\section{Hindawi}

Submit your manuscripts at

http://www.hindawi.com
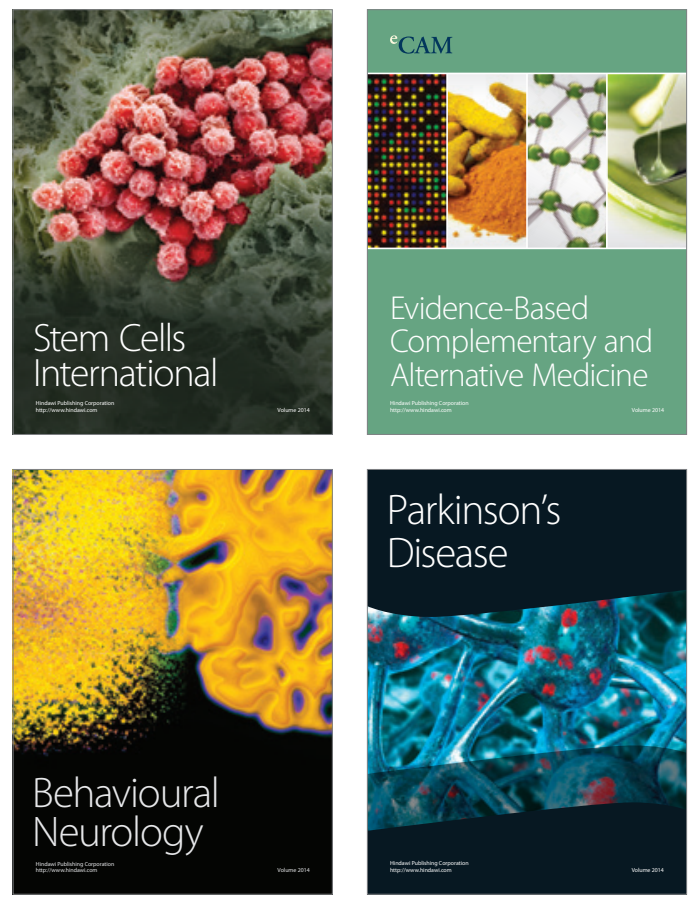
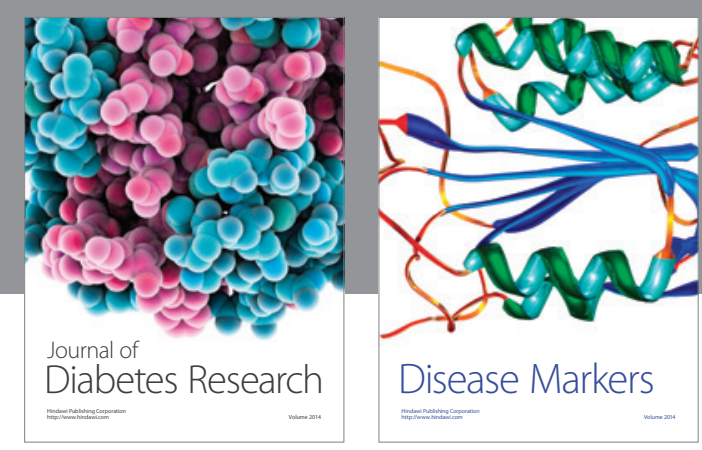

Disease Markers
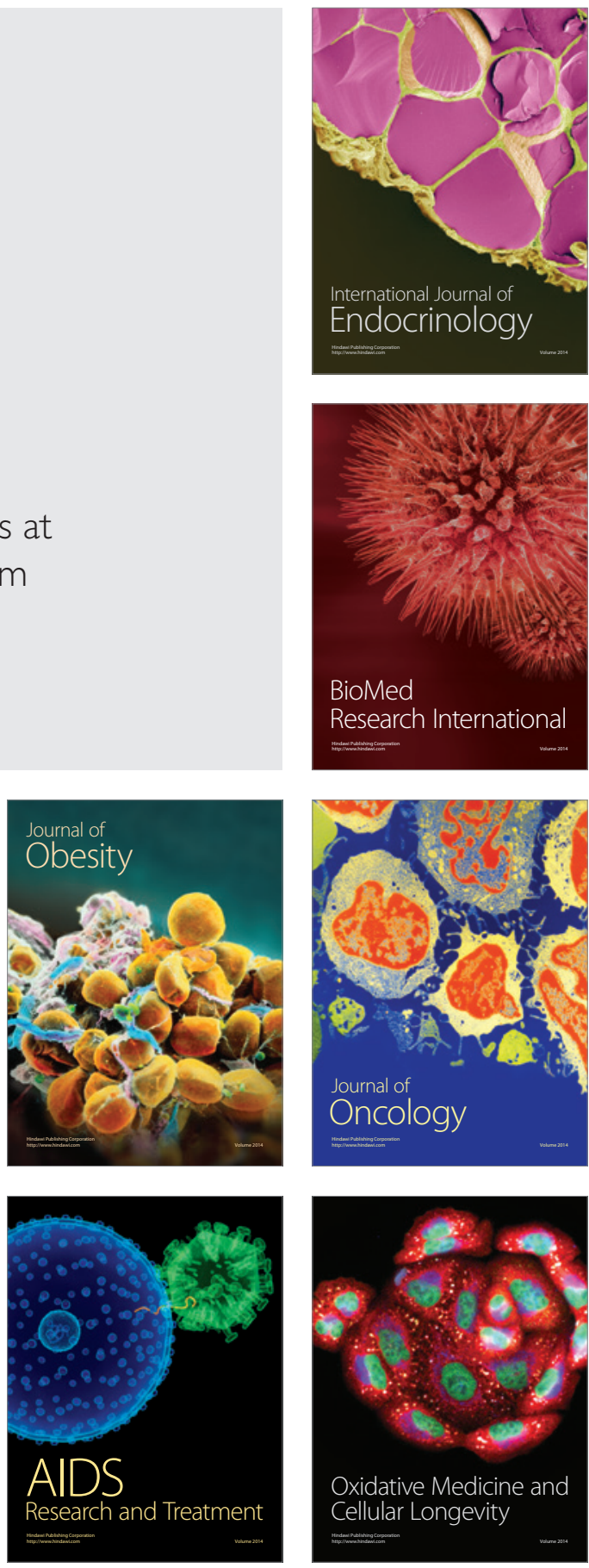